\title{
Preparation and Characterization of Lead-free Piezoelectric Ceramics
}

\author{
Qiang Chen ${ }^{1, a}$, Jinxu Li ${ }^{1, b}$, Lihui Zhang ${ }^{1}$, Yang Bai ${ }^{1}$, Yanjing Su ${ }^{1}$, Lijie Qiao ${ }^{1}$ \\ and Alex A. Volinsky ${ }^{2}$ \\ ${ }^{1}$ Corrosion and protection Center, Key Laboratory for Environmental Fracture (MOE), University of \\ Science and Technology Beijing, Beijing 100083, China \\ ${ }^{2}$ Department of Mechanical Engineering, University of South Florida, Tampa FL 33620 \\ a chenqiang30sf@163.com, ${ }^{b}$ jxli65@ustb.edu.cn (corresponding author)
}

Keywords: Sintering; Piezoelectric properties; Perovskites; $(\mathrm{K}, \mathrm{Na}) \mathrm{NbO}_{3}$

\begin{abstract}
K,Na) $\mathrm{NbO}_{3}$-based piezoelectric ceramics are promising candidates for practical applications of lead-free piezoelectric materials due to their excellent piezoelectric properties. In this paper, lead-free piezoelectric ceramics $\left(\mathrm{K}_{0.44} \mathrm{Na}_{0.52} \mathrm{Li}_{0.04}\right)\left(\mathrm{Nb}_{0.86} \mathrm{Ta}_{0.10} \mathrm{Sb}_{0.04}\right) \mathrm{O}_{3}$ (KNL-NTS) were successfully fabricated by traditional ceramics processing. The effects of sintering temperature on the structure, density and electrical properties of KNL-NTS ceramics were investigated. Crystal phases of both calcined powders and KNL-NTS ceramics have orthorhombic structure similar to that of $\mathrm{KNbO}_{3}$ ceramics. The piezoelectric coefficient first increases and then decreases with sintering temperature in the $1100-1180{ }^{\circ} \mathrm{C}$ range. KNL-NTS ceramics sintered at $1160{ }^{\circ} \mathrm{C}$ shows the maximum piezoelectric coefficient of about $199 \mathrm{pC} \cdot \mathrm{N}^{-1}$ and the maximum remnant polarization of $18.75 \mu \mathrm{C} \cdot \mathrm{cm}^{-2}$, with the corresponding $10.95 \mathrm{kV} \cdot \mathrm{cm}^{-1}$ coercive field and $4.74 \mathrm{~g} / \mathrm{cm}^{3}$ density.
\end{abstract}

\section{Introduction}

Lead-based piezoelectric materials such as $\mathrm{Pb}(\mathrm{Zr}, \mathrm{Ti}) \mathrm{O}_{3}(\mathrm{PZT})$ ceramics are widely used in practical applications due to their superior piezoelectric performance [1]. However, the volatilization of lead in the preparation and disposal processes brings a series of vital environmental problems, since lead is a toxic substance. For the sake of protecting the environment, many lead-free piezoelectric ceramics have been developed to replace the lead-based ceramics. Among various promising lead-free piezoelectric ceramics, potassium sodium niobate $(\mathrm{K}, \mathrm{Na}) \mathrm{NbO}_{3}(\mathrm{KNN})$-based ceramics has been considered to be a good candidate for the lead-free piezoelectric ceramics because of its high Curie temperature and large electromechanical coupling factors [2-4]. However, pure KNN ceramics are difficult to fully densify by ordinary sintering methods due to the high volatility of alkaline elements at high temperatures, resulting in non-optimized properties [5-6]. Hot-pressing technique as well as spark plasma sintering have been used to obtain high densities [2], but such processing techniques are not appropriate for industrial applications because of high cost. Thus, introducing modifiers to form solid solutions with $\mathrm{KNN}$ by replacing $\mathrm{A}$ and/or $\mathrm{B}$ site cations of the $\mathrm{ABO}_{3}$ perovskite structure has been widely used to prepare KNN-based ceramics by conventional solid state sintering methods [7-13].

In this paper, lead-free piezoelectric ceramics $\left(\mathrm{K}_{0.44} \mathrm{Na}_{0.52} \mathrm{Li}_{0.04}\right) \quad\left(\mathrm{Nb}_{0.86} \mathrm{Ta}_{0.10} \mathrm{Sb}_{0.04}\right) \mathrm{O}_{3}$ (KNL-NTS) were synthesized by traditional ceramics processing. The effects of sintering temperature on the structure, density and electrical properties of KNL-NTS ceramics were investigated.

\section{Sample Preparation}

KNL-NTS were prepared by conventional ceramics processing. Analytical grade metal oxides or carbonate powders of $\mathrm{K}_{2} \mathrm{CO}_{3}(99 \%), \mathrm{Na}_{2} \mathrm{CO}_{3}(99.8 \%), \mathrm{L}_{2} \mathrm{iCO}_{3}(99 \%), \mathrm{Nb}_{2} \mathrm{O}_{5}(99 \%), \mathrm{Ta}_{2} \mathrm{O}_{5}(99.99 \%)$, $\mathrm{Sb}_{2} \mathrm{O}_{5}(99 \%)$ and $\mathrm{CuO}(99 \%)$ were used as raw materials. The use of three different powders with carbonate origin requires extra care to be taken against humidity. Thermogravimetric analysis (TGA) 
shows that the powders lose weight up to $180^{\circ} \mathrm{C}$, equivalent to absorbed water [14]. Therefore, in order to obtain stoichiometric material composition all powders were separately dried in an oven at $200^{\circ} \mathrm{C}$ for $2 \mathrm{~h}$ prior to mixing. Raw materials were mixed according to stoichiometric ratio with the nominal composition of $\left(\mathrm{K}_{0.44} \mathrm{Na}_{0.52} \mathrm{Li}_{0.04}\right)\left(\mathrm{Nb}_{0.86} \mathrm{Ta}_{0.10} \mathrm{Sb}_{0.04}\right) \mathrm{O}_{3}$, followed by ball milling in an ethanol solution in a planetary ball mill using a plastic jar and zirconia grinding balls 3-10 mm in diameter. The batch was ball-milled at $300 \mathrm{rev} / \mathrm{min}$ for $5 \mathrm{~h}$. After milling the slurry was dried and kept in an oven at $100^{\circ} \mathrm{C}$.

Calcination was performed in alumina crucible heated to $120^{\circ} \mathrm{C}$ before the transfer of the dried powder. After powder transfer it was heated at $3{ }^{\circ} \mathrm{C} / \mathrm{min}$ rate to $830^{\circ} \mathrm{C}, 850{ }^{\circ} \mathrm{C}$ or $870{ }^{\circ} \mathrm{C}$ and kept at that temperature for $5 \mathrm{~h}$. X-ray diffraction (XRD) patterns of calcined powders obtained by this method are shown in Fig.1. Figure 1(a) shows that the reflections of raw materials disappear after calcining at three temperatures and the crystal phase of the sintered powders is orthorhombic, similar to that of $\mathrm{KNbO}_{3}$ (PDF\#77-0037M) ceramics. XRD patterns between $20^{\circ}$ and $35^{\circ}$ were enlarged in Fig. 1(b), implying that there is a second phase in powders sintered at $850{ }^{\circ} \mathrm{C}$ and $870{ }^{\circ} \mathrm{C}$, while powder sintered at $830{ }^{\circ} \mathrm{C}$ are pure. Therefore, the pre-sintering temperature was set at $830{ }^{\circ} \mathrm{C}$.

Aqueous polyvinyl alcohol (PVA) solution (9 wt.\%) was added into the powder as a binder to improve the quality of green bodies. Pellets with $15 \mathrm{~mm}$ diameter were uniaxially pressed at $6 \mathrm{MPa}$ for $50 \mathrm{sec}$.

The green bodies were sintered at $1100{ }^{\circ} \mathrm{C}, 1120^{\circ} \mathrm{C}, 1140{ }^{\circ} \mathrm{C}, 1160{ }^{\circ} \mathrm{C}$, or $1180{ }^{\circ} \mathrm{C}$ in air for $2 \mathrm{~h}$, respectively. The sintering procedure was as follows:

(a) Raising the temperature to $100^{\circ} \mathrm{C}$ at $10^{\circ} \mathrm{C} / \mathrm{min}$.

(b) Followed by heating to $600{ }^{\circ} \mathrm{C}$ at $5{ }^{\circ} \mathrm{C} / \mathrm{min}$ with dwell time of $3 \mathrm{~h}$ to completely remove organic additives.
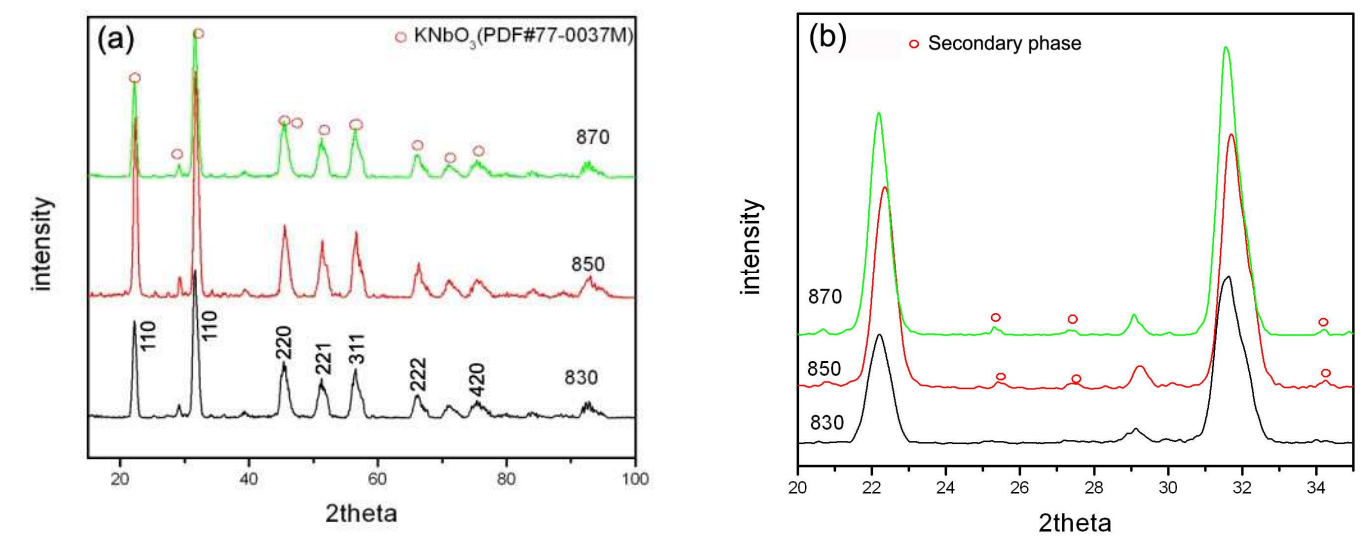

Fig.1. (a) XRD patterns of powders calcined at 830,850 and $870{ }^{\circ} \mathrm{C}$ and (b) enlarged XRD pattern between $20^{\circ}$ and $35^{\circ}$.
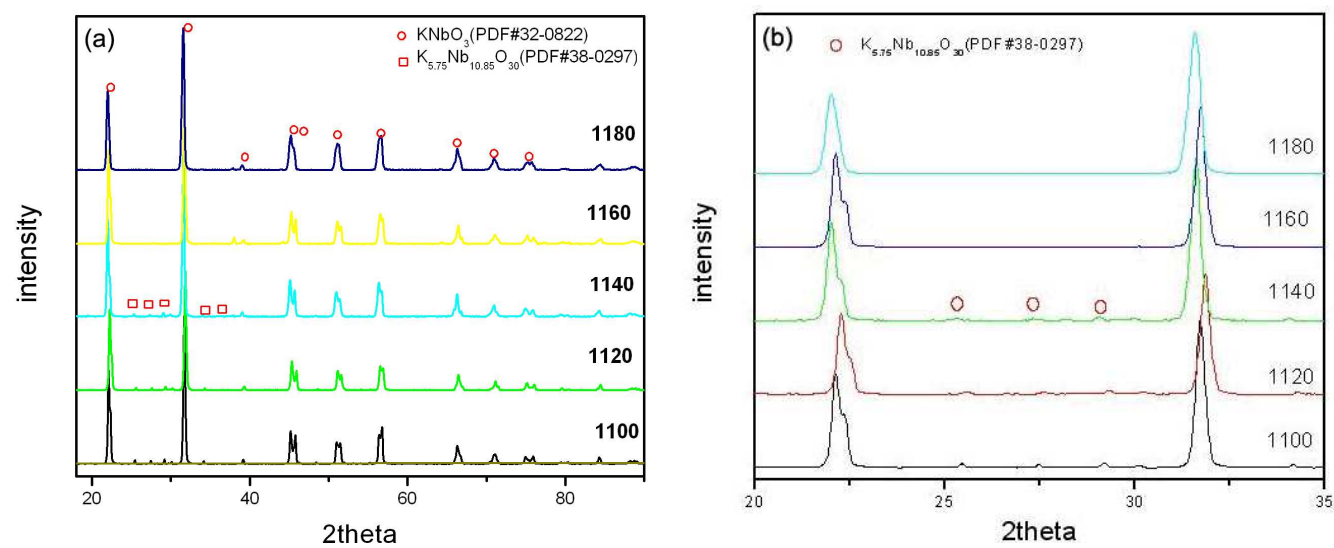

Fig.2. (a) XRD patterns of KNL-NTS ceramics sintered at different temperatures, and (b) enlarged XRD patterns between $20^{\circ}$ and $35^{\circ}$. 
(c) Finally heating to the sintered temperature at $5{ }^{\circ} \mathrm{C} / \mathrm{min}$ with $2 \mathrm{~h}$ dwell time.

Fig. 2 shows XRD patterns of KNL-NTS ceramics sintered at different temperatures. It can be concluded that: (1) The crystal phase of KNL-NTS ceramics has orthorhombic structure similar to that of calcined powders. (2) Samples sintered at $1100{ }^{\circ} \mathrm{C}, 1120^{\circ} \mathrm{C}$ or $1140{ }^{\circ} \mathrm{C}$ have a second phase, which is $\mathrm{K}_{5.75} \mathrm{Nb}_{10.85} \mathrm{O}_{30}$ ( $\mathrm{PDF} \# 38-0297$ ). The second phase disappears when the sintering temperature is up to $1160{ }^{\circ} \mathrm{C}$. (3) XRD pattern of ceramics sintered at $1160{ }^{\circ} \mathrm{C}$ is more similar to that of $\mathrm{KNbO}_{3}$ (PDF\#77-0037M) ceramics than that of other samples. Scanning electron microscopy (SEM) image of ceramics sintered at $1160^{\circ} \mathrm{C}$ is shown in Fig. 3.

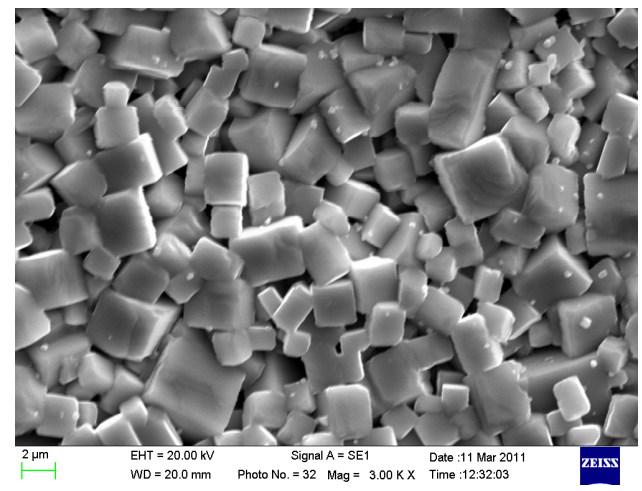

Fig.3. SEM images of KNL-NTS ceramics sintered at $1160^{\circ} \mathrm{C}$.

Table 1. Shrinkage of ceramics sintered at different temperatures.

\begin{tabular}{ccc}
\hline Sintered temp. $\left[{ }^{\circ} \mathrm{C}\right]$ & Diameter $[\mathrm{mm}]$ & Shrinkage $[\%]$ \\
\hline 1100 & 12.94 & 13.7 \\
\hline 1120 & 12.84 & 14.4 \\
\hline 1140 & 12.76 & 14.9 \\
\hline 1160 & 12.16 & 18.9 \\
\hline 1180 & 11.68 & 22.1 \\
\hline
\end{tabular}

KNL-NTS ceramics density can be characterized by measuring the linear shrinkage of sintered sample's diameter. Table 1 shows the diameter of samples sintered at different temperatures (original diameter of green body is $15 \mathrm{~mm}$ ). It can be seen that the shrinkage increases with the sintering temperature, implying that the density of sintered ceramics increases with sintering temperature. The density of KNL-NTS ceramics sintered at $1160^{\circ} \mathrm{C}$ is $4.74 \mathrm{~g} / \mathrm{cm}^{3}$, measured by the Archimedes method using distilled water as a medium. It is difficult to get the theoretical density of KNL-NTS ceramics because of its complex structure. KNL-NTS ceramics has higher density compared with the theoretical density of $\left(\mathrm{K}_{0.65} \mathrm{Na}_{0.35}\right) \mathrm{NbO}_{3}, 4.64 \mathrm{~g} / \mathrm{cm}^{3}$, indicating that the sintered samples are relatively dense.

\section{Characterization}

Piezoelectric Coefficient. The $\mathrm{d}_{33}$ piezoelectric coefficient was measured by a quasi-static $\mathrm{d}_{33}$ meter (ZJ-6A, Institute of Acoustics, Beijing, China). Fig. 4 shows the relationship between the piezoelectric coefficient $d_{33}$ and the sintering temperature, in which each point is an average of 8 data points with an error bar of standard deviation. Fig.4 indicates that the piezoelectric coefficient first increases and then decreases with sintering temperature. The piezoelectric coefficient reaches a maximum of $199 \mathrm{pC} \cdot \mathrm{N}^{-1}$ for the KNL-NTS ceramic sintered at $1160{ }^{\circ} \mathrm{C}$. When the sintering temperature was below $1160{ }^{\circ} \mathrm{C}$, the density of KNL-NTS ceramics increased with sintering temperature along with the piezoelectric coefficient increase. Above $1160{ }^{\circ} \mathrm{C}$ the piezoelectric coefficient began to decrease with sintering temperature. This may probably be due to the volatilization of alkali components during the sintering, which occurred during KNL-NTS ceramics sintering and caused composition deviation from the starting one. 


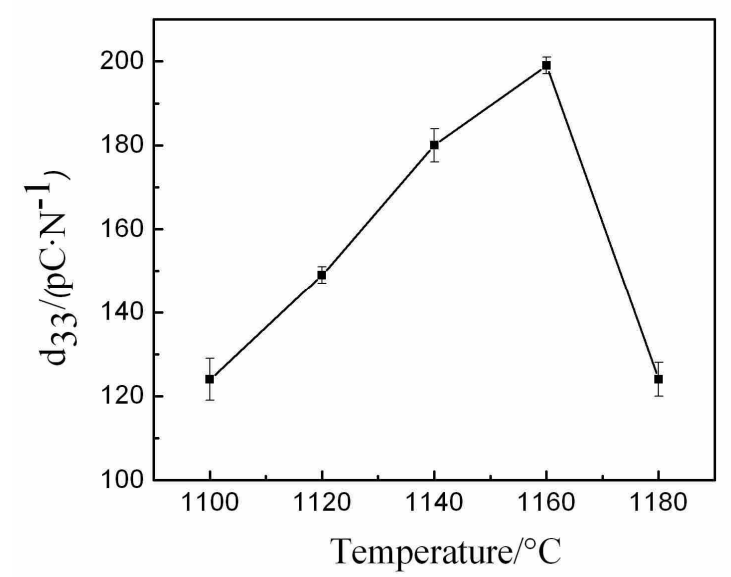

Fig.4. Piezoelectric coefficient $\mathrm{d}_{33}$ change with sintering temperature.

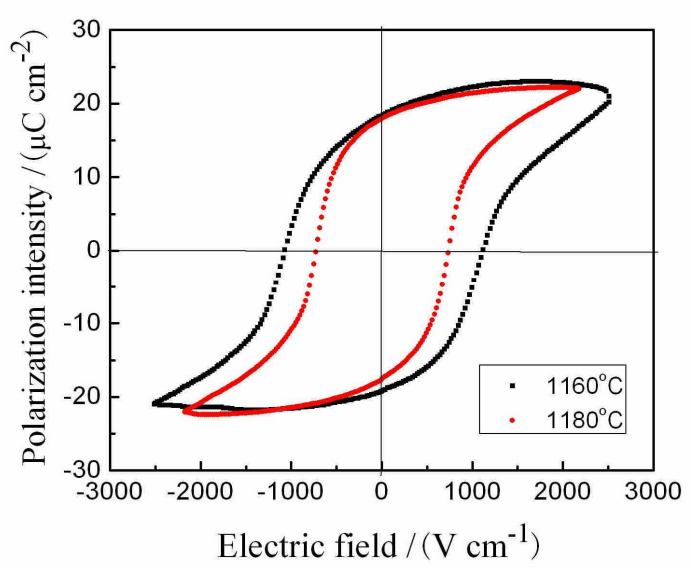

Fig.5. P-E hysteresis loops of KNL-NTS ceramics sintered at 1160 and $1180{ }^{\circ} \mathrm{C}$.

Hysteresis Loops. Generally, the existence of remnant polatization-coercive field (P-E) hysteresis loops is considered as evidence that material is ferroelectric. In this study, saturated P-E hysteresis loops confirm the ferroelectric nature of KNL-NTS ceramics. The coercive field and remnant polarization of KNL-NTS ceramics sintered at different temperatures are shown in Table 2.

Table 2. The coercive field and remnant polarization of KNL-NTS ceramics sintered at different temperatures.

\begin{tabular}{ccc}
\hline Sintering temp. $\left[{ }^{\circ} \mathrm{C}\right]$ & Coercive field $\mathrm{E}_{\mathrm{c}}\left[\mathrm{kV} \cdot \mathrm{cm}^{-1}\right]$ & Remnant polarization $\mathrm{P}_{\mathrm{r}}\left[\mu \mathrm{C} \cdot \mathrm{cm}^{-2}\right]$ \\
\hline 1100 & 8.56 & 11.10 \\
\hline 1120 & 9.72 & 12.02 \\
\hline 1140 & 11.30 & 15.94 \\
\hline 1160 & 10.95 & 18.75 \\
\hline 1180 & 7.34 & 17.65 \\
\hline
\end{tabular}

The coercive field $\mathrm{E}_{\mathrm{c}}$ increases with sintering temperature in the $1100{ }^{\circ} \mathrm{C}-1140{ }^{\circ} \mathrm{C}$ range. When the sintering temperature is $1140{ }^{\circ} \mathrm{C}$, the coercive field $\mathrm{E}_{\mathrm{c}}$ achieves its maximum of $11.30 \mathrm{kV} \cdot \mathrm{cm}^{-1}$, and further decreases with sintering temperature. The trend of remnant polarization $\mathrm{P}_{\mathrm{r}}$ is similar to the coercive field $\mathrm{E}_{\mathrm{c}}$, except the maximum value of remnant polarization, $18.75 \mu \mathrm{C} \cdot \mathrm{cm}^{-2}$, corresponds to the sintering temperature of $1160{ }^{\circ} \mathrm{C}$. Then the remnant polarization $\mathrm{P}_{\mathrm{r}}$ drops a little at the sintering temperature of $1180{ }^{\circ} \mathrm{C}$. The P-E hysteresis loops of KNL-NTS ceramics sintered at $1160{ }^{\circ} \mathrm{C}$ and $1180^{\circ} \mathrm{C}$ are shown in Fig.5.

\section{Discussion}

KNL-NTS ceramics were produced using conventional sintering in this study. Although the maximum piezoelectric coefficient of $199 \mathrm{pC} \cdot \mathrm{N}^{-1}$ is lower than $290 \mathrm{pC} \cdot \mathrm{N}^{-1}$ reported by Liang [15], the nominal composition in their work is $\left(\mathrm{K}_{0.465} \mathrm{Na}_{0.465} \mathrm{Li}_{0.07}\right)\left(\mathrm{Nb}_{0.95} \mathrm{Sb}_{0.05}\right) \mathrm{O}_{3}$, not the same as here. The value of $199 \mathrm{pC} \cdot \mathrm{N}^{-1}$ is very close to $195 \mathrm{pC} \cdot \mathrm{N}^{-1}$ for $\left(\mathrm{K}_{0.38} \mathrm{Na}_{0.52} \mathrm{Li}_{0.04}\right)\left(\mathrm{Nb}_{0.86} \mathrm{Ta}_{0.10} \mathrm{Sb}_{0.04}\right) \mathrm{O}_{2.97}$ sintered at $1125^{\circ} \mathrm{C}$ for $8 \mathrm{~h}$, and is better than $170 \mathrm{pC} \cdot \mathrm{N}^{-1}$ for the sample sintered at $1125^{\circ} \mathrm{C}$ for $2 \mathrm{~h}$ obtained by Rubio-Macros et al [8]. Moreover, $199 \mathrm{pC} \cdot \mathrm{N}^{-1}$ is much higher than $54 \mathrm{pC} \cdot \mathrm{N}^{-1}$ and 103 $\mathrm{pC} \cdot \mathrm{N}^{-1}$ for $\left(\mathrm{K}_{0.44} \mathrm{Na}_{0.52} \mathrm{Li}_{0.04}\right)\left(\mathrm{Nb}_{0.86} \mathrm{Ta}_{0.10} \mathrm{Sb}_{0.04}\right) \mathrm{O}_{3}$ sintered at $1125^{\circ} \mathrm{C}$ for $2 \mathrm{~h}$ and $8 \mathrm{~h}[8]$, respectively, which nominal composition same as here. Additionally, the piezoelectric coefficient achieved in this paper is higher than that of hot-pressing $115 \mathrm{pC} \cdot \mathrm{N}^{-1}[6]$ or spark plasma sintering $148 \mathrm{pC} \cdot \mathrm{N}^{-1}$ [2]. This indicates that there is more space to improve piezoelectric properties of lead-free ferroelectric 
ceramics through optimizing chemical composition and sintering process. In any case improved properties are related to keeping material free of humidity and as close to stoichiometric composition as possible.

\section{Conclusions}

A study of lead-free piezoelectric ceramics preparation and characterization using conventional powder synthesis was conducted. Some of the interesting aspects related to preparation and properties can be summarized as the following:

Lead-free KNL-NTS ceramics were produced successfully by sintering at $1100-1180{ }^{\circ} \mathrm{C}$ for $2 \mathrm{~h}$ under normal pressure. In this temperature range, the piezoelectric coefficient of KNL-NTS ceramics first increases and then decreases with the sintering temperature. KNL-NTS ceramics sintered at 1160 ${ }^{\circ} \mathrm{C}$ shows a maximum $199 \mathrm{pC} \cdot \mathrm{N}^{-1}$ piezoelectric coefficient. The sintering temperature was set as 1160 ${ }^{\circ} \mathrm{C}$ in the end. The coercive field Ec and remnant polarization $\mathrm{P}_{\mathrm{r}}$ of KNL-NTS ceramics sintered at $1160{ }^{\circ} \mathrm{C}$ are $10.95 \mathrm{kV} \cdot \mathrm{cm}^{-1}$ and $18.75 \mu \mathrm{C} \cdot \mathrm{cm}^{-2}$, respectively.

\section{Acknowledgements}

This work is supported by National Nature Science Foundation of China (51072021, 50632010). Alex Volinsky acknowledges support from the National Science Foundation.

\section{References}

[1] B. Jaffe, W.R. Cook, H. Jaffe: Piezoelectric Ceramics. Academic Press, New York, USA, 1971.

[2] J.F. Li, K. Wang, B. P. Zhang, et al.: J. Amer. Ceram. Soc. Vol. 89(2006), p.706.

[3] D.M. Lin, K.W. Kwok and H.W.L. Chan: Appl. Phys. Lett. Vol. 91(2007), p.3513.

[4] E. Hollensterin, M. Davis, D. Damjanovic, et al.: Appl. Phys. Lett. Vol. 87(2005), p.2905.

[5] L. Egerton and D.M. Dillom: J. Amer. Ceram. Soc. Vol. 42(1959), p.438.

[6] R.E. Jaeger and L. Egerton: J. Amer. Ceram. Soc. Vol. 45(1962), p.209.

[7] P. Zhao, B. P. Zhang and J. F. Li: Appl. Phys. Lett. Vol. 90(2007), 2909.

[8] F. Rubio-Marcos, P. Ochoa and J.F. Fernandex: J. Eur. Ceram. Soc. Vol. 27(2007), p.4125.

[9] H.L. Du, F.S. Tang, D.J. Liu, et al.: Mater. Sci. Eng. B Vol. 136(2007), p.165.

[10] Y. Guo, K. Kakimoto and H. Ohsato: Solid State Comm. Vol. 129(2004), p.279.

[11] Z.P. Yang, Y.F. Chang, B. Liu, et al.: Mater. Sci. Eng. A Vol. 432(2006), p.292.

[12] Y.T. Lu, X.M. Chen, D.Z. Jin, et al.: Mater. Res. Bull. Vol. 40(2005), p.1847.

[13] Y. Guo, K. Kakimoto and H. Ohsato: J. Phys. Chem. Solids. Vol. 65 (2004), p.1831.

[14] H. Birol, D. Damjanovic and N. Setter: J. Eur. Ceram. Soc. Vol. 26(2006), p.861.

[15] W.F. Liang, D.Q. Xiao and W.J. Wu: Curr. Appl. Phys. Vol. 11(2011), p.1. 
Testing and Evaluation of Inorganic Materials II

10.4028/www.scientific.net/KEM.492

Preparation and Characterization of Lead-Free Piezoelectric Ceramics 10.4028/www.scientific.net/KEM.492.189 